\title{
AR \& VR Based Child Education in Context of Bangladesh
}

\author{
Md. Salah Uddin*, Mahmudur Rahman, Md. Nahid Hasan, Dr. Shaikh Muhammad Allayear, Mizanur Rahman, Md.
} Samaun Hasan and Shah Muhammad Sadiur Rahman

Department of Multimedia and Creative Technology, Daffodil International University, Dhaka, Bangladesh

DOI: $10.36348 /$ sjeat.2019.v04i12.005 $\quad$ | Received: 30.11.2019| Accepted: 07.12.2019| Published: 30.12 .2019

*Corresponding author: Md. Salah Uddin

\section{Abstract}

Now day's children are more likely to use smartphones. They would like to use smartphones more than a textbook. They use smartphones for playing various games and watch the cartoon as well as funny videos and movies also. The addiction to using smartphones through children is increasing day by day. Maximum parents now want to teach their children via smartphones. In that case, they try to find various learning apps and games. From that sense, we decide to make a child learning apps by using Augmented Reality \& Virtual Reality. AR \& VR is the most powerful way of interaction nowadays. On AR apps we design an alphabets book for the children according to our survey report and we make an android app using unity 3D. When a child opens the apps, then the phone camera will open. And if the child holds the camera in any picture of the book, then the smartphone will tell the name of the alphabet and also tell a word with that particular word and will show a 3D visual model of the object on the mobile display. And on the VR apps, we design some $3 \mathrm{~d}$ environments according to our survey. Inside the environment, there will some alphabets in some fixed placed according to sequence and the child has to collect them by walking inside the environment. When he/she pick any alphabet than the apps will tell the name of the alphabet.

Keywords: Augmented Reality, Virtual Reality, Child Education, Smartphone, Animation, Game, 3D.

Copyright @ 2019: This is an open-access article distributed under the terms of the Creative Commons Attribution license which permits unrestricted use, distribution, and reproduction in any medium for non-commercial use (NonCommercial, or CC-BY-NC) provided the original author and source are credited.

\section{INTRODUCTION}

In Bangladesh approximately $70 \%$ children use mobilephone. Generally they use mobile phone watching cartoon and playing games. Our basic purpose of this project is to make a child learning apps by using Augmented Reality \& Virtual Reality. Because of children are more interested in a smartphone than their book in this century. So we decide to make something which helps to teach the children. For that, we make these interesting smartphone apps by relating to smart technology for those children who are addicted to mobile phones. AR brings works sheets or flashcards to our life. It can represent static images in a magical way while simplifying and visualizing complex ideas, making them easier to understand. For example, a flower bud on a printed page could bloom in AR slowly.

The 3D nature of AR inspires children to work together in groups; it creates genuine cooperation and improves communication. The overlay of the real world and dream additionally get youngsters thinking fundamentally with respect to how it functions and where the enlarged article truly is. It is anything but difficult to utilize which enables kids and gives them the fulfilment that they are responsible for their learning, at home or school. This self-coordinated learning builds its concentration and data maintenance. It rouses and connects with the offspring of all capacities to learn.

It's useful for educators as well. They can rapidly make a fun learning condition at a moderately minimal effort. AR is effectively executed, effectively learned and simple to refresh as good as ever substance ends up accessible. AR is a definitive fun, play-based movement and holds tremendous potential for ECE. As a prominent child parenting Master Maggie Dent, says often "children do not have to change. The world around them has to change". AR places kids in the driver's seat. The essential exercise that children need to learn is that they are the makers. Innovation is only an empowering influence.

Virtual Reality (VR) to date has had a more prominent profile, picked up its prominence through gaming and you have to put resources into headsets and supporting equipment. $94 \%$ of UK educators believe that VR will be helpful in the classroom, appeared by a 
Lenovo report. $42 \%$ anticipate that it will be typical inside 5 years. VR isn't gone for ECE with real producers of VR headsets advertising them as being fitting for children more than 13 years of age influence.

We would like to create an Augmented and Virtual reality application for mobile devices by which children who would like to learn using smartphones and technology.

\section{OVERVIEW OF CHILD EDUCATION IN BANGLADESH}

In Bangladesh there is no AR \& VR based child education system. The education system in Bangladesh is so much monotonous. Child are facing problem our education system. They cannot go through the real world, they only memorize some contents.

Before start working we make a survey to know about parents and child requirements. Because we want to make the app's user-friendly, attractive and interactive to the child. The survey helps us to know about their psychology and help us to make interactive apps for the child

First, we select 10 parents of school-going children. After that, we give them a form with a few questions. We name that "Requirements Analysis from Parents". Here the results of our survey report.

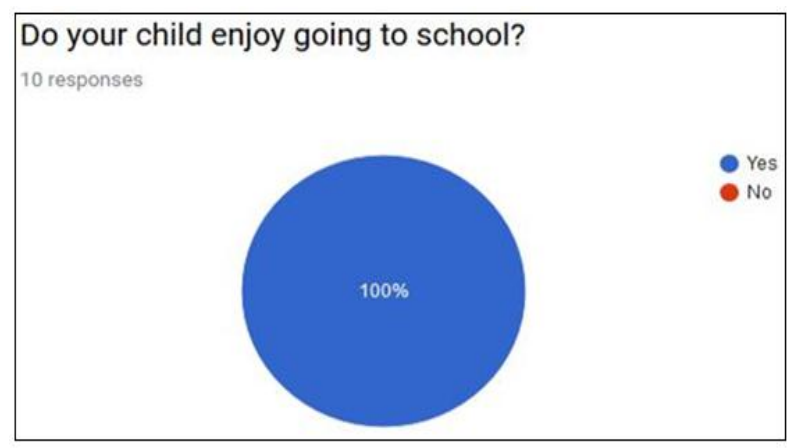

Fig-1: Result of child enjoyment going to school

From this survey, we know from the parents that their children enjoy going to school.

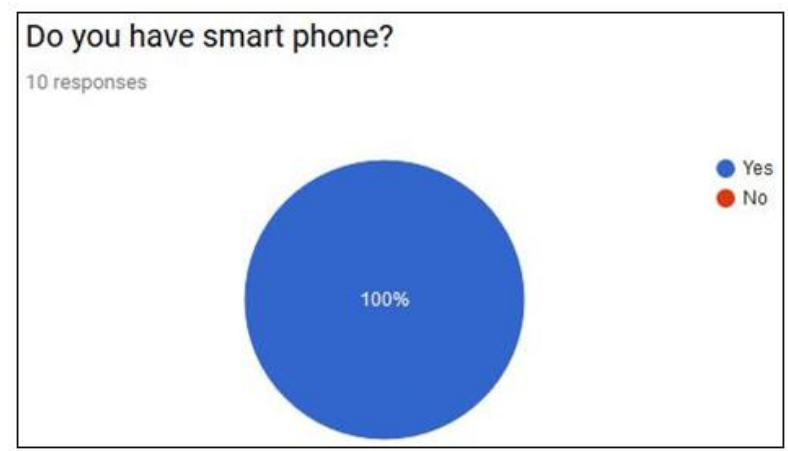

Fig-2: Result of smartphone availability of a parent
From this survey, we know from the parents that they have smartphone.

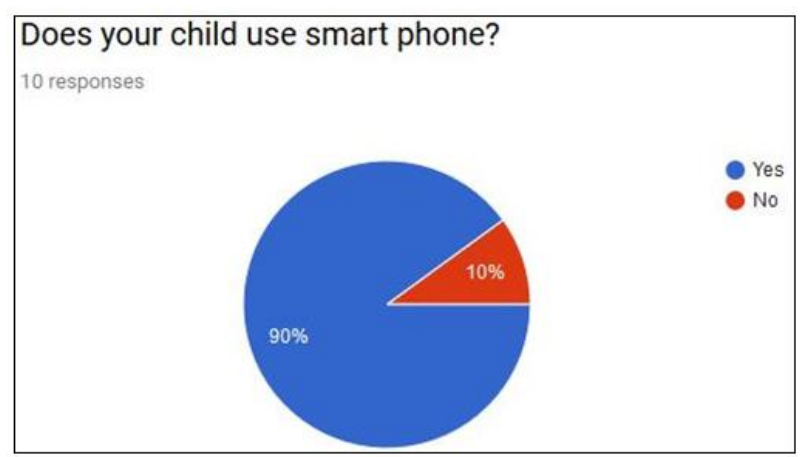

Fig-3: Result of smartphone use of a child

From this survey, we know that $90 \%$ child use their parent"s smartphone.

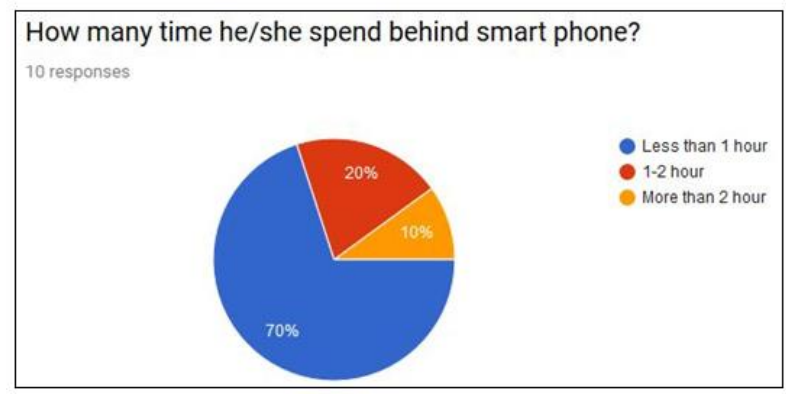

Fig-4: Result of spending time on smartphone

From this survey, we know that $70 \%$ of children use their smartphones less than 1 hour, $20 \%$ of children use their parentes smartphone 1-2 hours and $10 \%$ of children use their parent ${ }^{\text {ee }} \mathrm{s}$ smartphone more than 2 hours.

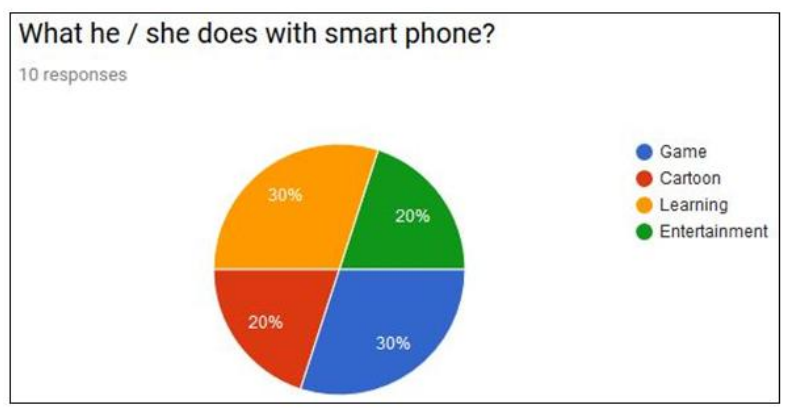

Fig-5: Result of activities on smartphone

From this survey, we know that $30 \%$ of children use the smartphone for playing the game, $30 \%$ children use the smartphone for learning purpose, $20 \%$ of children use rhe smartphone for watching cartoon and rest of $20 \%$ use smartphone on entertainment purpose. 
Salah Uddin et al., Saudi J Eng Technol, Dec. 2019; 4(12): 514-521

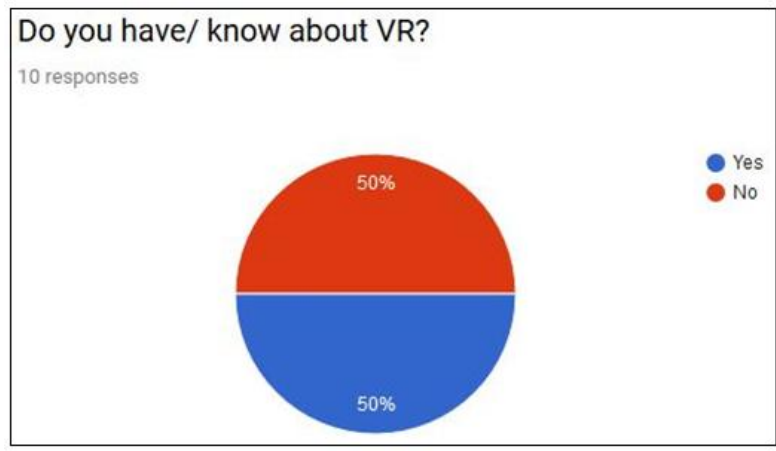

Fig-6: Result of idea about VR

From this survey, we know that $50 \%$ of parents know about VR and 50\% not know about VR.

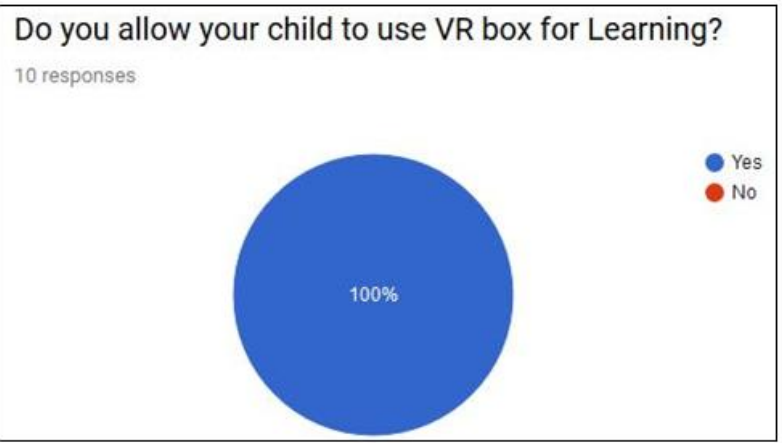

Fig-7: Result of accessibility of VR Box

From this survey, we know that $100 \%$ of parents will allow using VR Box for learning to their child.

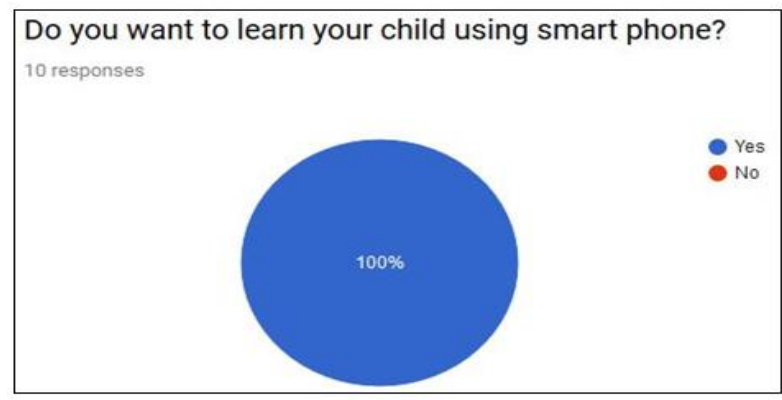

Fig-8: Result of learning using smartphone

From this survey, we know that $100 \%$ of parents will allow using the smartphone for learning to their child.

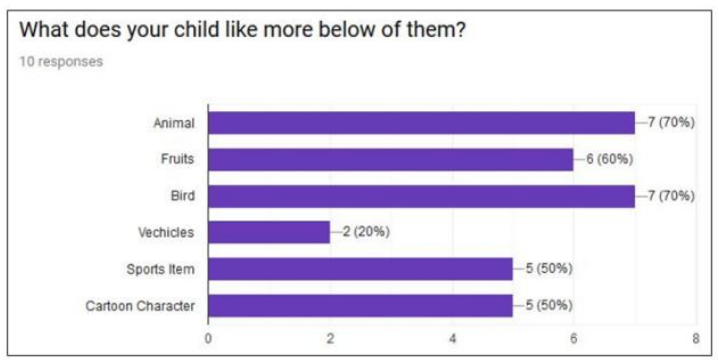

Fig-9: Result of children preference contents
From this survey, we know the interested items of children. From this report we make decision about our models of the game.

After that we asked some question to their child of those 10 parents about their requirements. We named the survey is "Child Requirements Analysis".

Here the results of our survey.

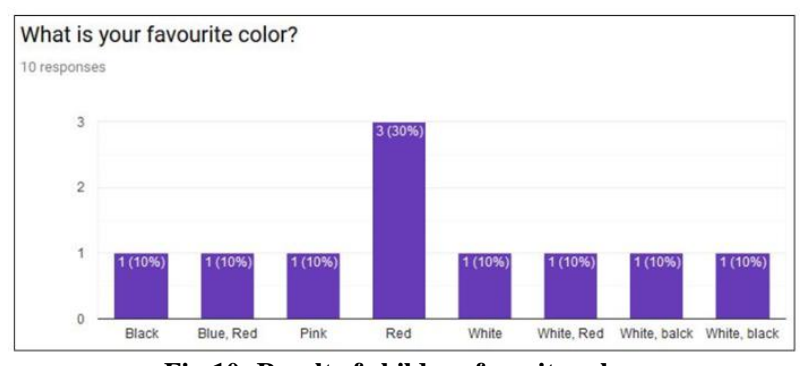

Fig-10: Result of children favorite color

From this survey we learn about the color choice of child. We found $30 \%$ children like Red most. $10 \%$ pink, $10 \%$ Blue-Red, $10 \%$ Pink, $10 \%$ white, $10 \%$ white-Red and $20 \%$ white black. It helps us about color sense for our model and design.

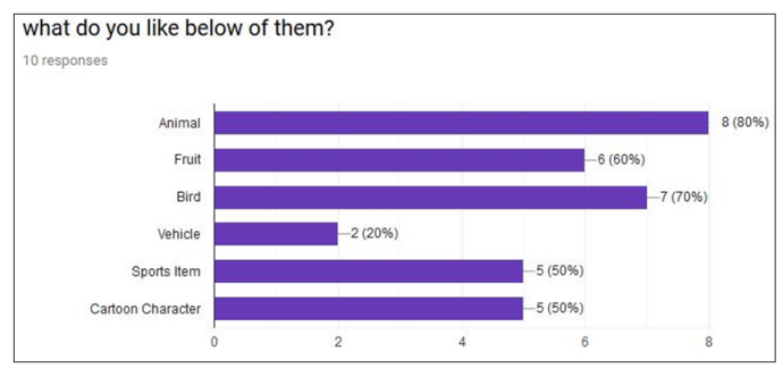

Fig-11: Result of children favorite contents

From this survey we know the interested items of children. From this report we make decision about our models of the game.

\section{METHODS OF DEVELOPMENT}

We have developed two applications to teach children. One is Alphabet AR application and another is Alphabet VR Application.

\section{Alphabet AR Book Design}

First of all, we did book design for the "Alphabet AR Book" application by Adobe Illustrator software. We have created a basic book page template design for the "Alphabet AR Book" application. 


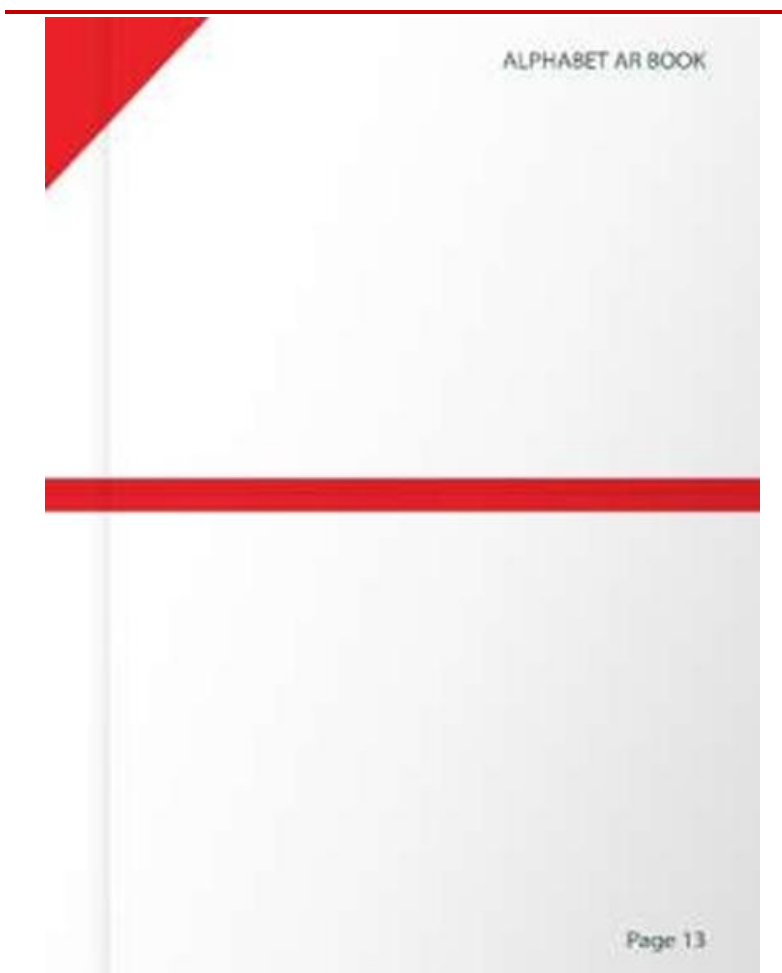

Fig-12: Basic book page template design for "Alphabet AR Book"

We have created book cover and back page.

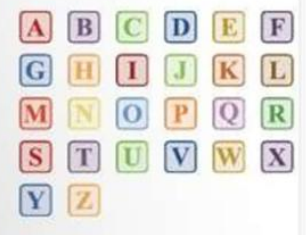

Y 2

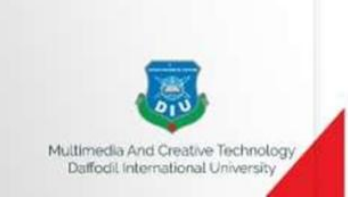

Fig-13: AR book cover and back page design

We modelled our content using Autodesk Maya software.

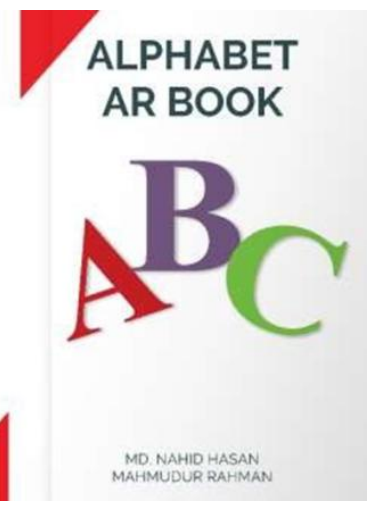




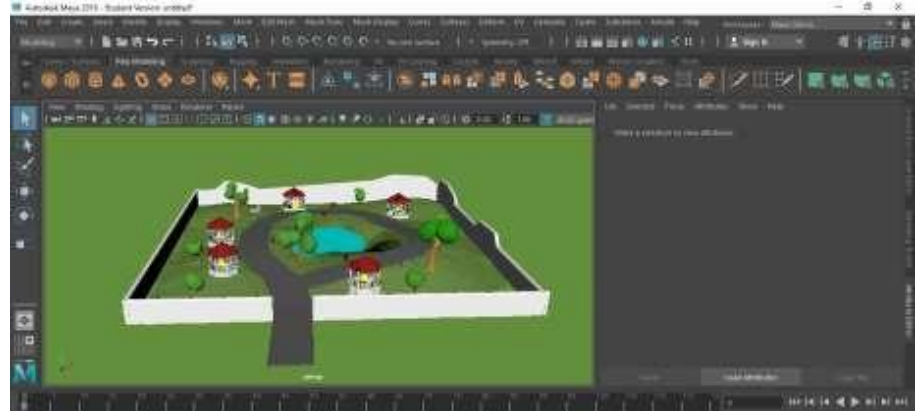

Fig-16: 3d model level design by Autodesk Maya

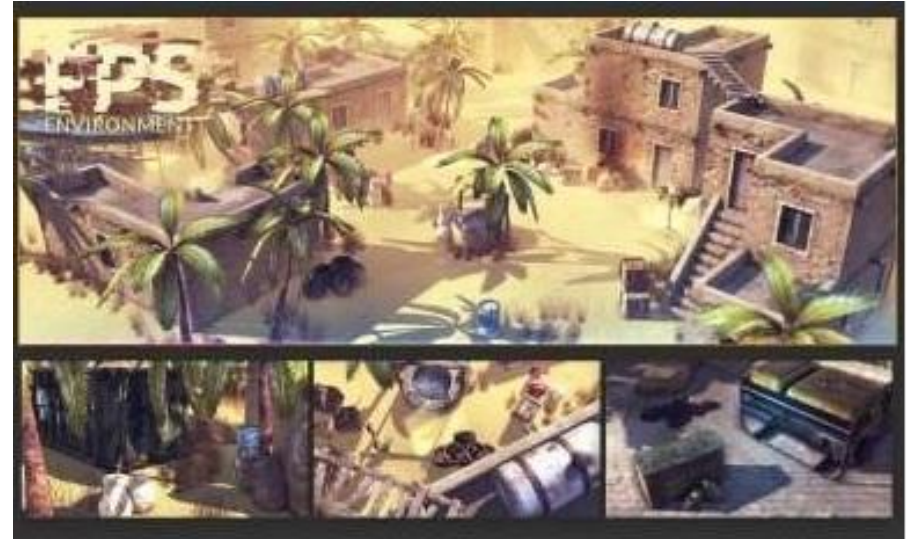

Fig-17: 3d model level design by Autodesk Maya

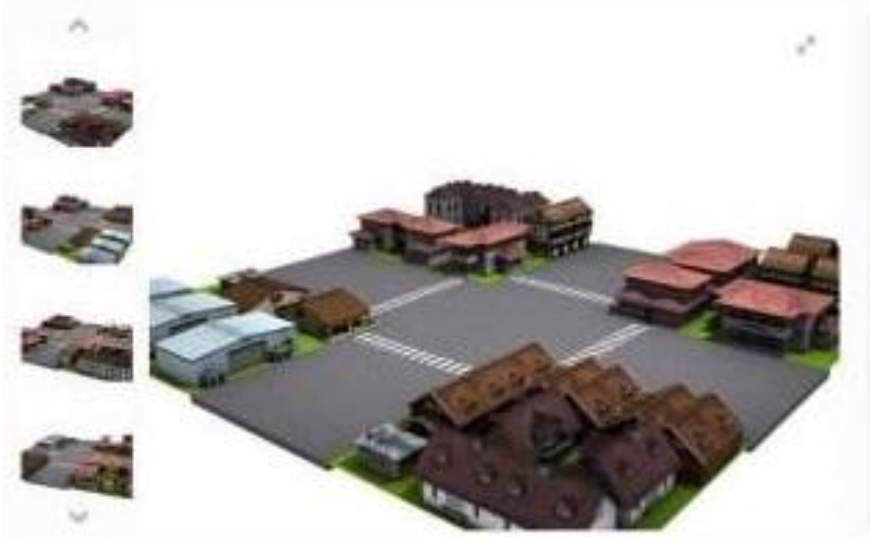

Fig-18: 3d model level design by Autodesk Maya

Five level of "Alphabet VR Game" application. First level, we created environment scene in unity. Take Empty Game Object renames "Player" and add character controller, add audio source component. "Player" child Main Camera.

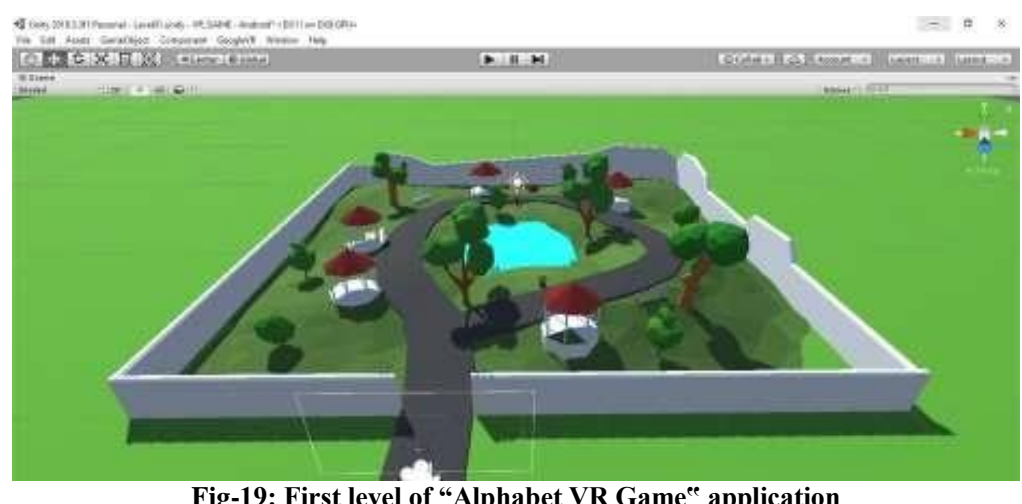

Fig-19: First level of "Alphabet VR Game"e application 
We created UI inventory system in "Alphabet VR Game” application.

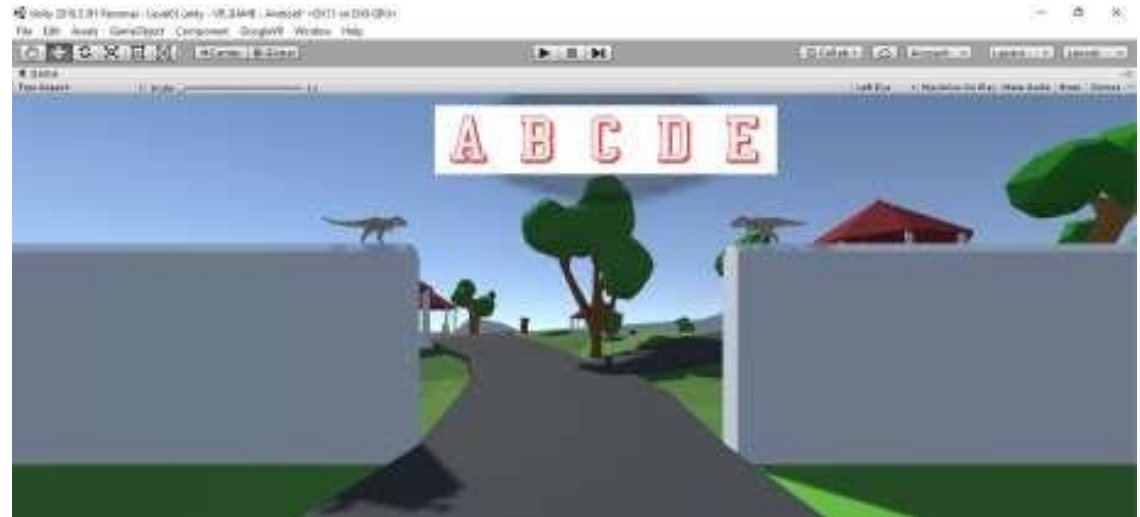

Fig-20: Inventory system in “Alphabet VR Game” application Same way creates other level of "Alphabet VR Game” application.

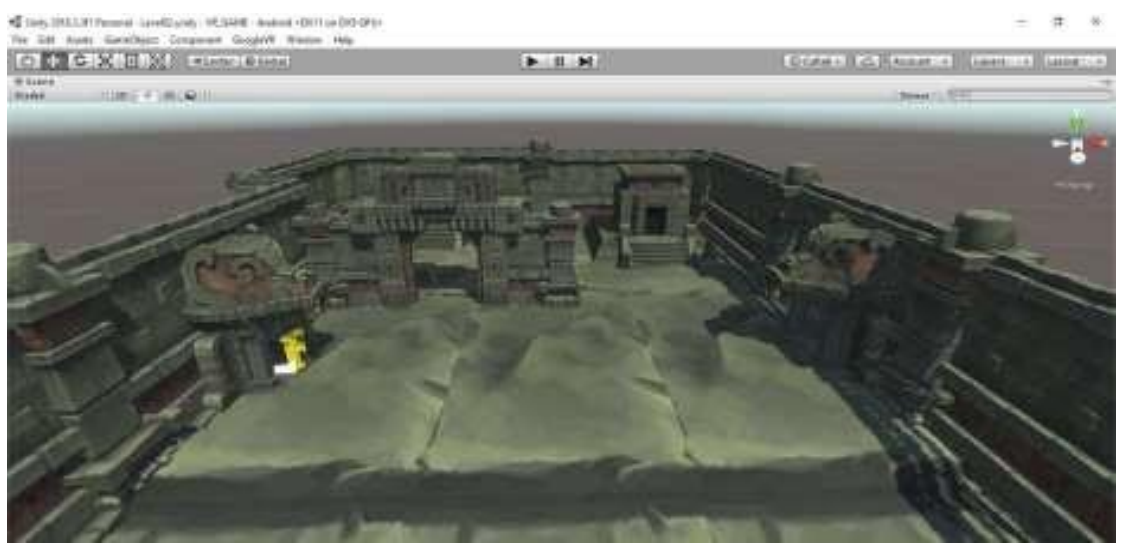

Fig-21: Second level of “Alphabet VR Game” application

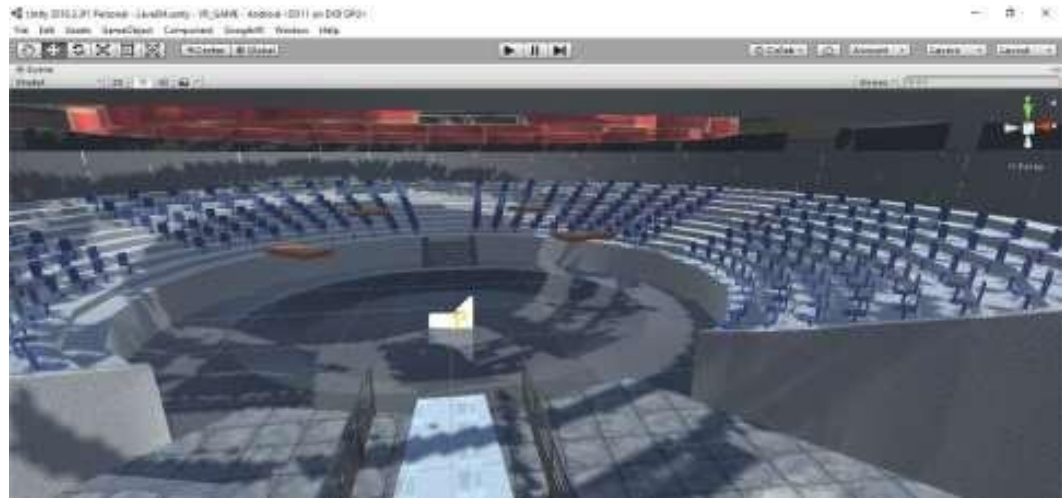

Fig-22: Third level of "Alphabet VR Game” application

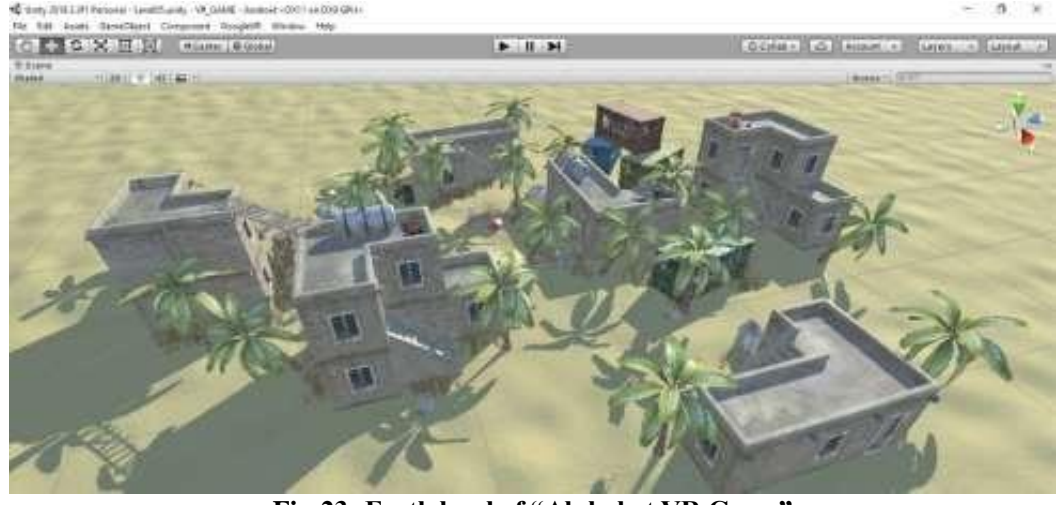

Fig-23: Forth level of "Alphabet VR Game" 


\section{EXPERIMENTAL RESULT}

After completing building, we again meet with those children and offer them to use our application. After that, we collect their evaluation. The result of this survey is below:

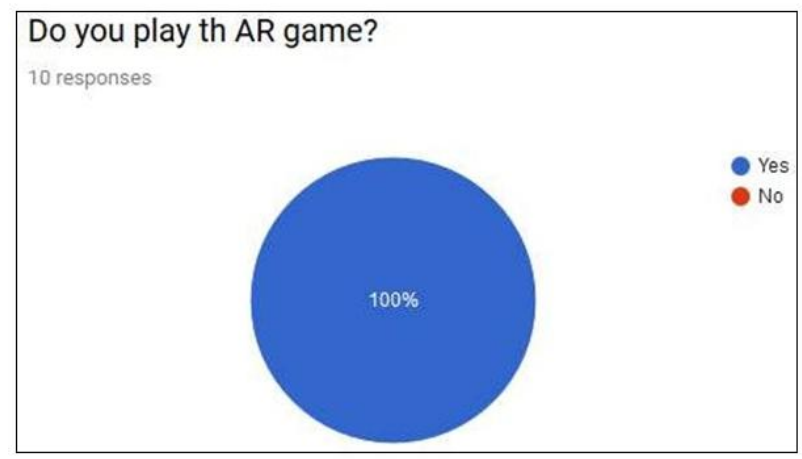

Fig-24: Result of play AR game

\section{Do you enjoy the game?}

10 responses

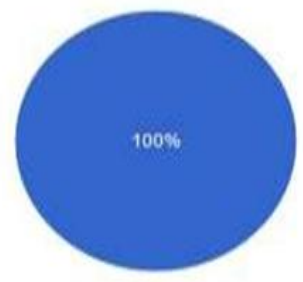

Fig-25: Result of enjoy the game

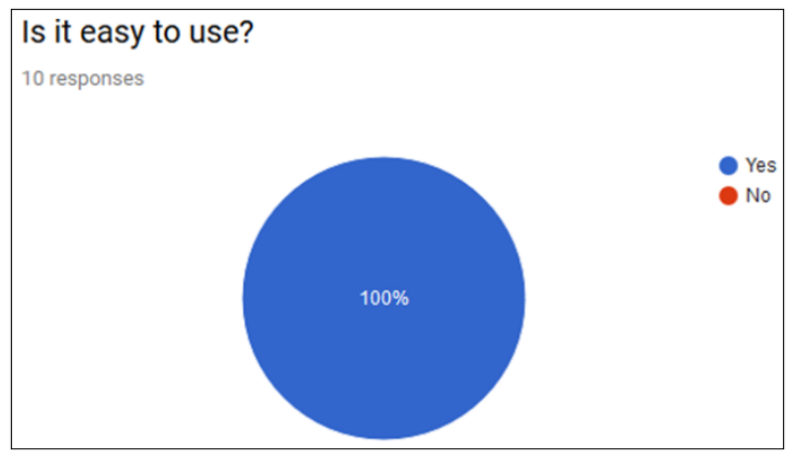

Fig-26: Result of the easy to use

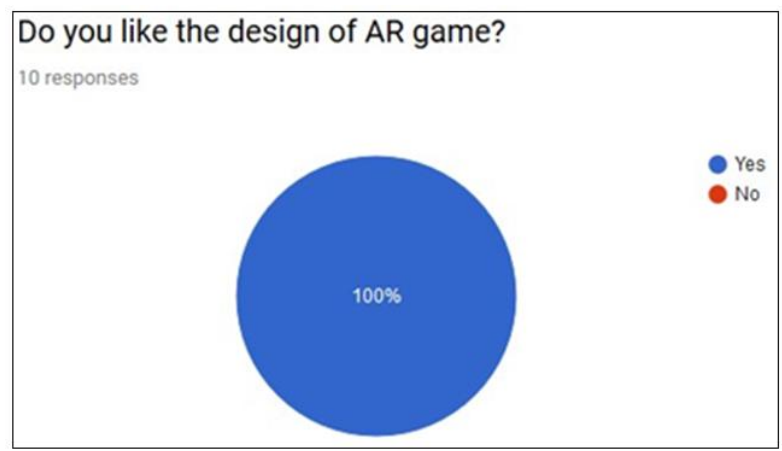

Fig-27: Result about the design

Every child likes the design of the AR game.

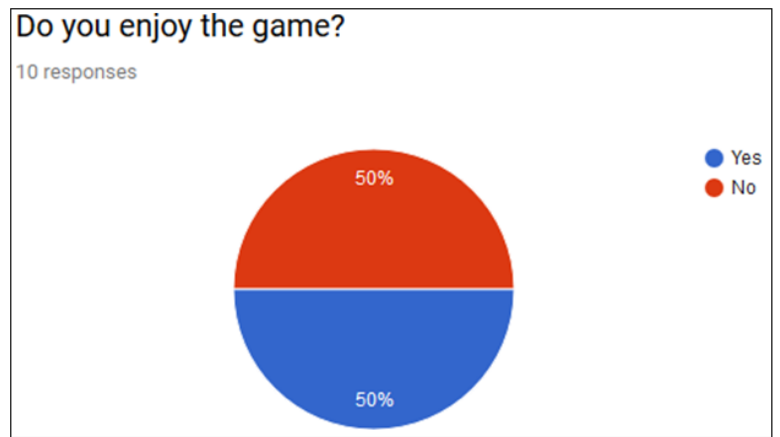

Fig-28: Result of enjoy game

$50 \%$ of children enjoy the VR game and the rest of $50 \%$ didn't enjoy it.

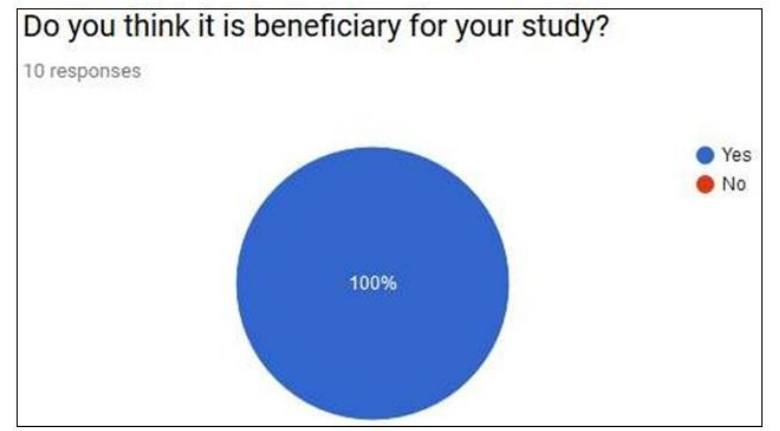

Fig-29: Result of think beneficiary

Every child thinks our AR apps and VR game is beneficiary for their study.

\section{CONCLUSION AND FUTURE WORK}

In this century, human life has been widely affected by the electronic devices around them, and the rate is still growing. Some experts also believe that this social media-based society is actually breaking the bondage between humans and humanity is under a threat too. But there must be ways to use every tool in a positive way because the tools are not controlling us, rather we are responsible as the users. So, if we can clarify our way of thinking, way of using the opportunities science has offered to us, we definitely can make a better future.

This system also can be made to control more smart devices. For example, it may be designed to serve as a smart education system in Augmented Reality and Virtual Reality application. As the Augmented Reality and Virtual Reality technology are growing, automated education system control is another emerging technology, both of this idea can be merged to produce smart book apps and game apps. These apps Augmented Reality and Virtual Reality control system.

This project was just a beginning. More attractions, services and inspirations will help this endeavour to reach its utmost success of creating a modern society. Where modern education will not only be inside books and paper, but modern education will 
symbolize modern technique to learning and teaching, above all modern ways of looking at life.

\section{ACKNOWLEDGEMENTS}

We would like to thank all the colleagues at the Dept. of Multimedia and Creative Technology, Daffodil International University for their feedback and useful recommendations that contributed in bringing this paper to its final form.

\section{REFERENCES}

1. Veronica, S. P. Reasons to Use Virtual Reality in Education and Training Courses and a Model to Determine When to Use Virtual Reality. Themes In Science And Technology Education Special Issue, Pages 59-70. Klidarithmos Computer Books.

2. Nor Farhah Saidin1, Noor Dayana Abd Halim1 \& Noraffandy Yahaya. (2015). A Review of Research on Augmented Reality in Education: Advantages and Applications. International Education Studies, 8(13). Published by Canadian Center of Science and Education.

3. https://en.wikipedia.org/wiki/Augmented_reality. [Access: 04/03/2019]
4. https://en.wikipedia.org/wiki/Virtual_reality. [Access: 04/03/2019]

5. https://en.wikipedia.org/wiki/FBX [Access: 05/03/2019]

6. https://free3d.com/ [Access: 07/03/2019]

7. https://www.coursera.org/ [Access: 12/03/2019]

8. https://en.wikipedia.org/wiki/Adobe_After_Effects [Access: 19/03/2019]

9. https://en.wikipedia.org/wiki/Google_Cardboard [Access: 05/04/2019]

10. https://en.wikipedia.org/wiki/Autodesk_Maya [Access: 05/04/2019]

11. https://en.wikipedia.org/wiki/Unity_(game_engine ) [Access: 15/04/2019]

12. https://en.wikipedia.org/wiki/Microsoft_Visual_St udio [Access: 15/04/2019]

13. https://en.wikipedia.org/wiki/Adobe_ Illustrator. [Access: 15/04/2019]

14. https://forum.unity.com/threads/how-to-changescenes-by-pressing-a-key.277249/[Access: 05/04/2019]

15. http://www.devassets.com/ [Access: 01/05/2019]

16. https://assetstore.unity.com/ [Access: 20/05/2019]

17. https://en.wikipedia.org/wiki/Vuforia_Augmented _Reality_SDK [Access: 20/05/2019. 